\title{
A Study on Cone Factors for Northeastern Part of Shiwha Area II:Reliability and Soil Properties
}

\author{
Dae-Kyu Kim ${ }^{1 *}$ \\ ${ }^{1}$ Dept. of Civil Engineering, Sangmyung University \\ 시화지구 북동지역에서의 콘 계수 연구 II: \\ 신뢰도 및 토질정수 \\ 김대규 $^{1^{*}}$ \\ ${ }^{1}$ 상명대학교 건설시스템공학과
}

\begin{abstract}
In this study, the values of the four kinds of cone factors $\left(N_{k t}, N_{k e}, N_{\Delta u}\right.$, and recently proposed $N_{e}$ ) and the soil properties, for the northeastern part of Shiwha area, were investigated. The measured and calculated undrained strengths, which have been obtained from the various experimental data, were compared with each other, and their relationship with the plastic index was also studied. The strength from the $N_{\Delta u}$ method was unexpectedly not reasonable and the higher values of cone factors were observed with the larger plastic index.

요 약 본 연구에서는, 시화지구 북동지역 지반에 대하여 네 가지 종류의 콘계수 값들( $N_{k t}, N_{k e}, N_{\Delta u}$, 최근 제안된 $N_{e}$ )과 지반의 특성치들과의 관계를 고찰하였다. 다양한 실험결과를 활용하여 계산한 비배수강도와 실제 측정된 비배 수강도를 비교하였으며, 이들 값들과 소성지수와의 관계를 분석하였다. $N_{\Delta u}$ 를 활용하여 구한 비배수강도는 의외로 좋은 결과를 보여주지 못했으며, 소성지수 값이 커질수록 콘계수 값이 커지는 현상이 고찰되었다.
\end{abstract}

Key Words : Plastic index, Undrained strength, Cone factor, Piezocone

\section{Introduction}

There have been generally three kinds of cone factors $\left(N_{k t}, N_{k e}, N_{\Delta u}\right)$ and a new cone factor $N_{e}$ was recently proposed for estimating undrained strength from the cone penetration test result(Campanella et al. 1984, Su et al. 2002, Kim et al. 2008, Kim 2009)[1-4]. The undrained strength is estimated from the value of the tip resistance $q_{t}$ minus total overburden stress $\sigma_{v o}$ over $N_{k t}$, the $q_{t}$ minus the pore pressure behind the cone tip $u_{2}$ over $N_{k e}$, the $u_{2}$ minus the static pore water pressure $u_{o}$ over $N_{\Delta u}$, or the $q_{t}$ minus $u_{o}$ over $N_{e}$.
In this study, the reliability of the undrained strength calculation using the four kinds of the cone factor values, for the soils in the northeastern part of Shiwha area, was investigated together with the plastic index, which is a representative soil property. The values of the four cone factors have been already estimated from the results of the piezocone, unconfined compression, UU triaxial compression, and vane shear testings(Kim 2011)[5]. The subsoil profiles, the water content variation, and the Atterberg limits are described in Table 1 and Fig. 1, respectively. 
[Tabel 1] Subsoil profiles

\begin{tabular}{|c|c|c|c|}
\hline depth $(\mathrm{m})$ & layer & USCS & $\mathrm{s}_{\mathrm{u}}\left(\mathrm{t} / \mathrm{m}^{2}\right)$ \\
\hline $6 \sim 16$ & sea sediment & $\mathrm{CL} / \mathrm{ML}$ & $1.0 \sim 5.0$ \\
\hline $15 \sim 25$ & sea sediment & $\mathrm{SM} / \mathrm{CL}$ & $0.3 \sim 4.0$ \\
\hline $10 \sim 30$ & bed rock & $\mathrm{SM}$ & $3.0 \sim 6.0$ \\
\hline
\end{tabular}

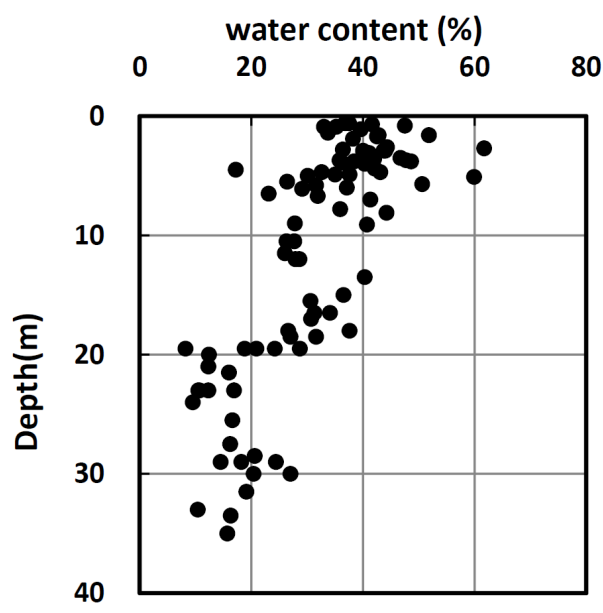

(a) variation of water content

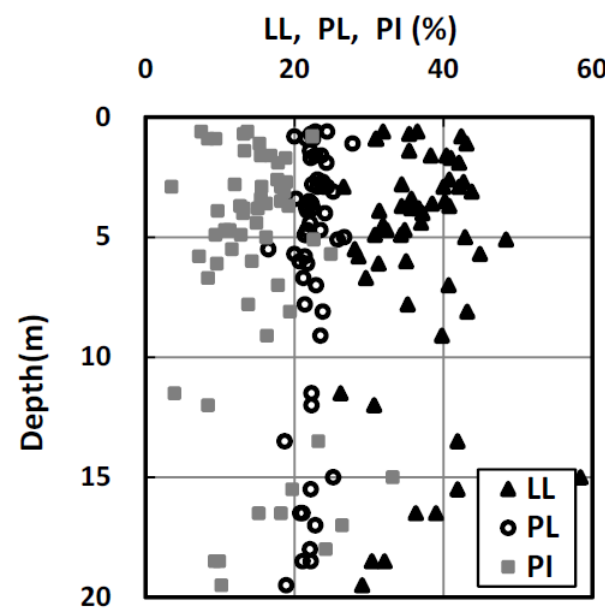

(b) Atterberg limits with depth

[Fig. 1] Soil properties

\section{Reliability of Cone Factor Method}

Fig. 2 presents the measured and calculated undrained strengths based on the four kinds of cone factors.

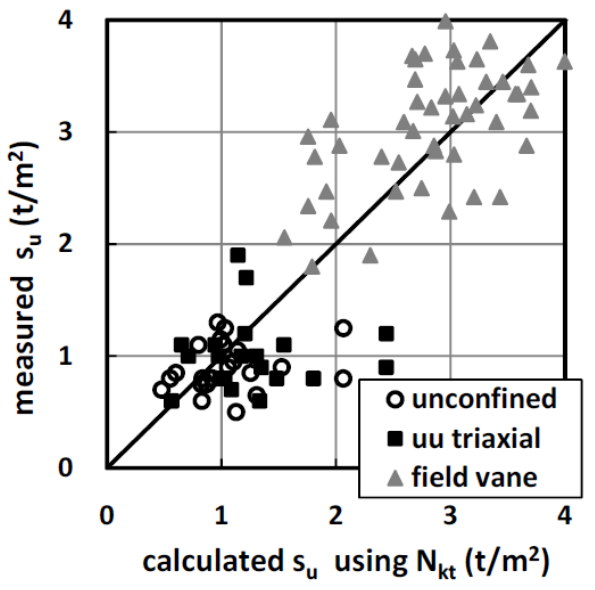

(a) based on $N_{k t}$

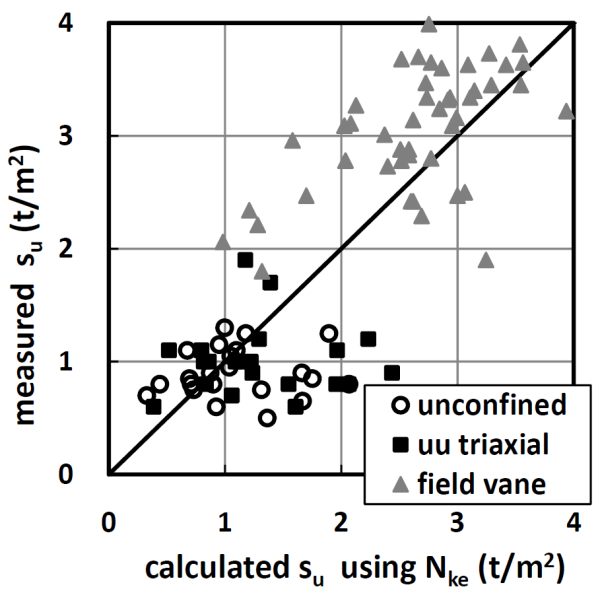

(b) based on $N_{k e}$

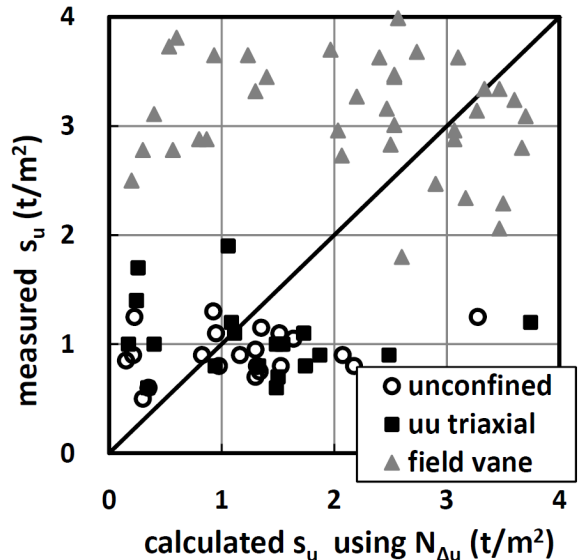

(c) based on $N_{\Delta u}$ 


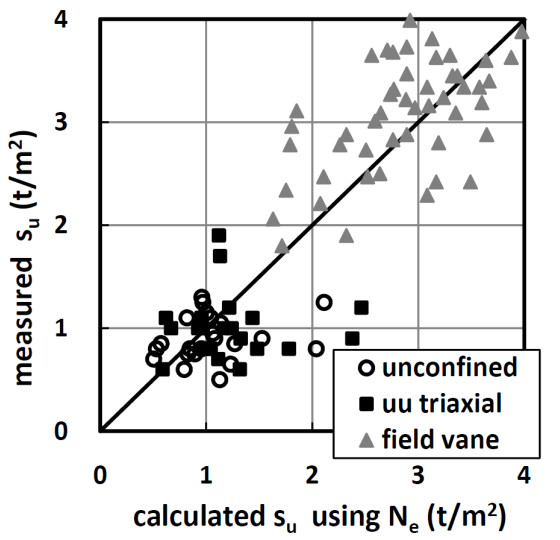

(d) based on $N_{e}$

[Fig. 2] Measured and calculated undrained strengths

The cone factor values used for calculation have been determined $12 \sim 39$ for $N_{k t}, 11 \sim 33$ for $N_{k e}, 3 \sim 8$ for $N_{\Delta u}, 13 \sim 42$ for $N_{e}(\operatorname{Kim} 2011)[5]$.

The reliability of the undrained strength calculation based on $N_{\Delta u}$, as shown in Fig. 2, did not produce a reasonable results. This is unexpected because $N_{\Delta u}$ is based on the $u_{2}$ and $u_{o}$, but the pore pressures like them have been considered as the relatively exact parameters indicating the situation of the soil behavior such as the consolidation status. The reason that the reliabilities based on $N_{k e}$ and $N_{e}$ are better than it based on $N_{\Delta u}$ is that they use only $u_{2}$ or $u_{o}$ but not both. The $N_{e}$ method seems to give a little bit better results than the $N_{k e}$ method, which can be since $u_{2}$ might be less stably measured during the testing process than the static pore water pressure $u_{o}$. It can be said that such methods using $u_{2}$ as $N_{k e}$ and $N_{\Delta u}$ methods should be carefully used in the case that $u_{2}$ is precisely measured.

\section{Cone Factor and Soil Property}

The pore pressure ratio $B_{q}\left(u_{2}\right.$ minus $u_{o}$ over $q_{t}$ minus $\left.\sigma_{v o}\right)$ and the plastic index, the representative soil property, are described in Fig. 3.

It is not likely that there is any relationship between the both quantities in Fig. 3 and previous studies(Lunne et al. 1985, 1997)[6][7]. However, the $B_{q}$ is a very constitutive item involving important factors such as the pore pressures, the overburden stress, and the tip resistance; therefore, it should be noted that the $B_{q}$ needs to be further studied. Fig. 4 presents the cone factors and the plastic index.

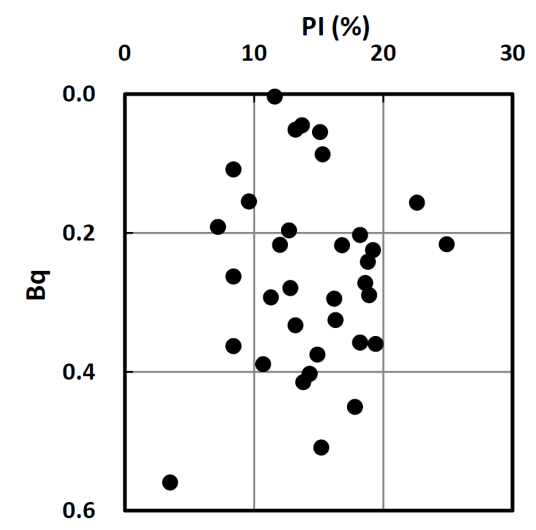

[Fig. 3] Plastic index with pore pressure ratio

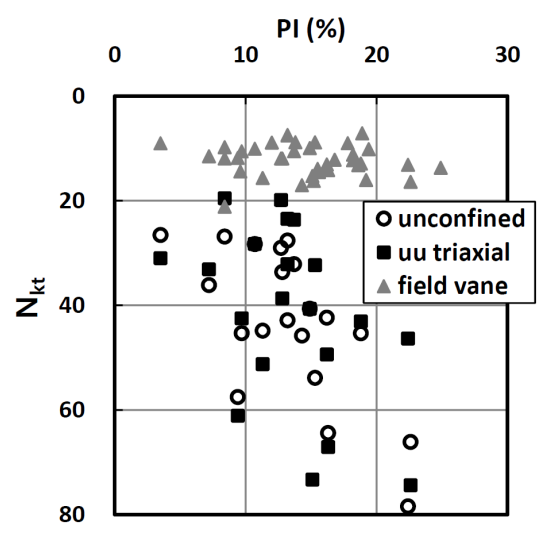

(a) Plastic index with $N_{k t}$
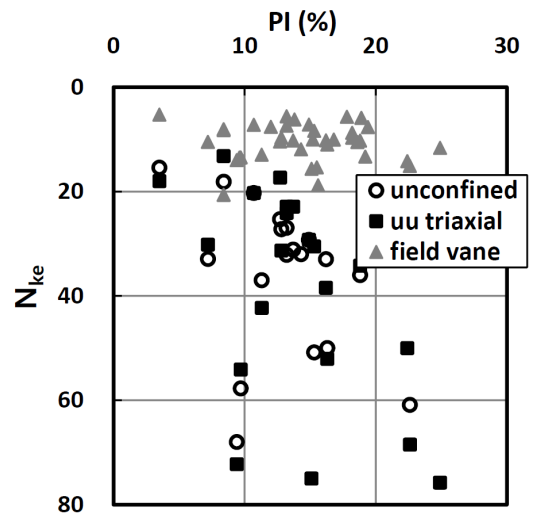

(b) Plastic index with $N_{k e}$ 


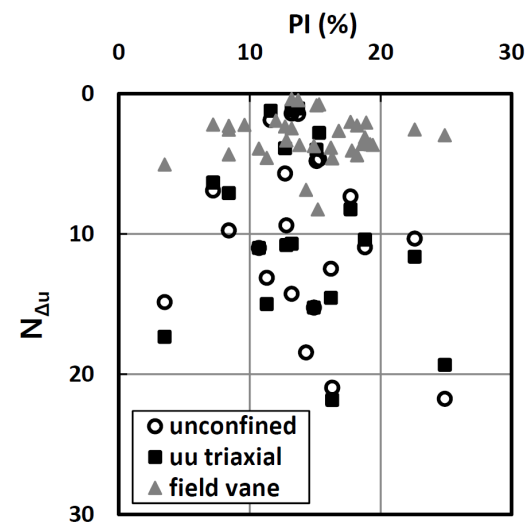

(C) Plastic index with $N_{\Delta u}$

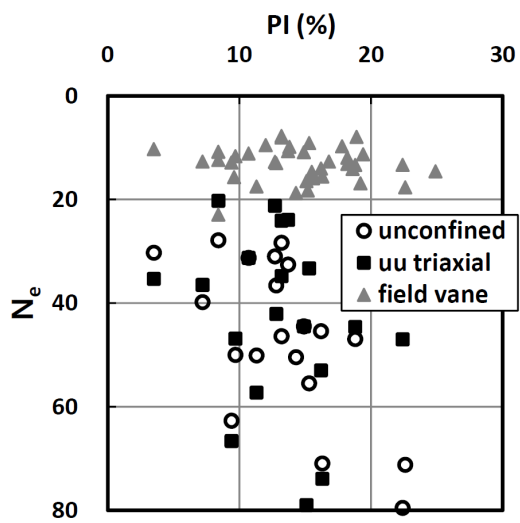

(d) Plastic index with $N_{e}$

[Fig. 4] Plastic index with cone factors

The values of the all four kinds of cone factors based on the field vane test rarely vary as plastic index, which is a very important soil property, and thus it is reasonable to determine the representative value for the site. On the other hand, the cone factor values based on the unconfined and UU triaxial testings clearly indicate, in a greater or less degree, the increasing tendency with the increase of the plastic index. This feature is a kind of new founding unlike in the previous studies(Kim et al. 2008, Lunne et al. 1985, 1997)[3][6][7]. As long as in this study, it could be recommended with caution that the representative value of cone factor should be determined according to the plastic index range. This is a sufficiently possible hypothesis but it needs a lot of data to reach an obvious conclusion.

Fig. 5 suggests the relationship between the plastic index and the ratio of the calculated to measured undrained strengths based on the four types of the cone factors. The ratio value of unity denotes the very high reliability in the calculation method of undrained strength based on a cone factor kind and a testing type.

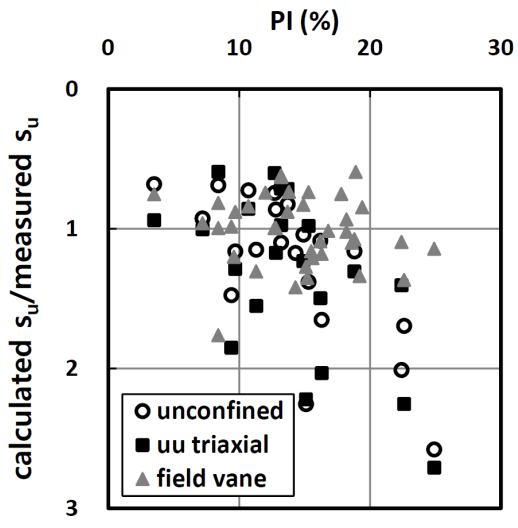

(a) based on $N_{k t}$

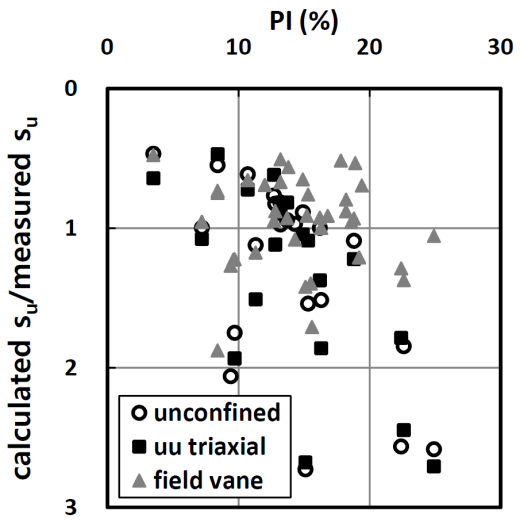

(b) based on $N_{k e}$

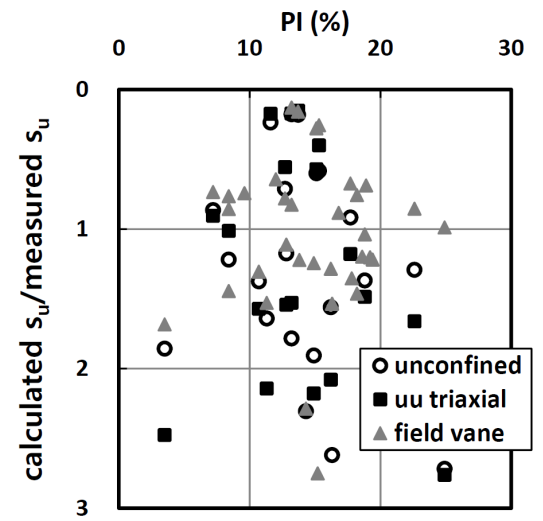

(c) based on $N_{\Delta u}$ 


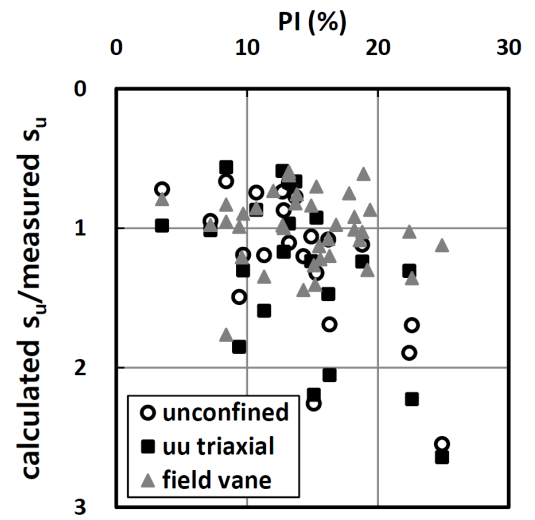

(d) based on $N_{e}$

[Fig. 5] Calculated and measure undrained strength with plastic index

For the three types of the cone factors except $N_{\Delta u}$, the ratio values from the field vane test result could be found in the narrower band near unity than those from the unconfined and UU triaxial test results. This meas that the field vane test is recommended as the testing type in which the undrained strength is obtained to get the cone factor value, on the other hand, it can be said that the $N_{\Delta u}$ method should be used with great caution. The fluctuation of the data in the $N_{\Delta u}$ method mainly results from the difficultness in measuring the pore pressures in the cone penetration test procedure.

The $N_{k t}$ and $N_{e}$ methods produced better results than the $N_{k e}$ and $N_{\Delta u}$ methods. This can be thought also due to the experimental hardship in measuring the precise pore water pressures. It might be concluded, as long as in this study, that the two cone factor methods based on $N_{k t}$ and $N_{e}$ could be recommended with the field vane testing for the reasonable result.

The ratio values for the plastic index values less than about 9 were generally underestimated for the three types of the cone factors except $N_{\Delta u}$. On the contrary, the ratio values were generally overestimated for the plastic index over 20. This tendency is growing for the unconfined and UU triaxial testings rather than for the field vane testing and the ratio tends to even increase with the increase of the plastic index for the two testings. The overestimation of the undrained strength might result in the opposite side of the conservative design. The range of the plastic index needs to be considered in the determination of the representative value of the cone factor.

\section{Conclusions}

In this study, the reliability of the four cone factor methods, which are based on the four kinds of cone factors $N_{k t}, N_{k e}, N_{\Delta u}$, and $N_{e}$, are investigated using the experimental results of the unconfined, UU triaxial, and field vane testings for soils of the northeastern part of Shiwha area. The relationships between the methods and the plastic index are also studied. The following conclusions could be made.

- The methods based on $N_{k t}$ and $N_{e}$ were more reliable than those based on $N_{k e}$ and $N_{\Delta u}$. Specially, the $N_{\Delta u}$ method did not give any reasonable results. This is due that the method uses both pore pressures $u_{2}$ and $u_{o}$.

- Any relationship was not observed between the pore pressure parameter and the plastic index. but the $B_{q}$ is so constitutive in soil characteristics that it needs further research.

- The representative value of the cone factors tend to vary with the plastic index. The plastic index range should be considered to determine the reasonable cone factor value.

- It might be concluded that the two cone factor methods based on $N_{k t}$ and $N_{e}$ could be recommended with the field vane testing considering the relationship between the plastic index and the ratio of the calculated to measured undrained strengths.

- The calculated undrained strength for the plastic index values less than about 9 were generally underestimated; however, it was generally overestimated for the plastic index over 20 .

\section{References}

[1] R. G. Campanella, P. K. Robertson, D. G. Gillespie, J. Greig, "Recent Developements in insitu Testing of Soils," Pro. 11th Int. Conf. on Soil Mechanics and 
Foundation Engineering, Sanfrancisco, pp. 849-854, Vol. 2, 1985.

[2] S. F. Su, H. J. Liao, "Influence of Strength Anisotropy on Piezocone Resistance in Clay," J. of Geotechnical and Geoenvironmental Engineering, pp. 166-173, Vol. 128, No. 2, Feb., 2002.

[3] C. Kim, S. Kim, J. Lee,, "Estimation of Undrained Shear Strength for Clays using Effective Cone Factor," J. of Korean Society of Geotechnical Engineers, pp. 133-141, Vol. 24, No. 11, 2008.

[4] D. Kim, "Interpretation of Empirical Cone Factors for Determining Undrained Strength," J. of Korea Academia -Industrial Cooperation Society, pp. 3296-3301, Vol. 10, No. 11, November, 2009.

[5] D. Kim, "A Study on Cone Factors for Northeastern Part of Shiwaha Area I: Evaluation and Pore Pressure Parameter," J. of Korea Academia-Industrial Cooperation Society, in press.

[6] T. Lunne, H. P. Chrisoffersen, T. I. Tjelta, "Engineering Use of Piezocone Data in North Sea Clays," Pro. 11th Int. Conf. on Soil Mechanics and Foundation Engineering, Sanfrancisco, pp. 907-912, Vol. 2, 1985.

[7] T. Lunne, P. K. Robertson, J. J. M. Powell, Cone Penetration Testing, Blackie Academic and Professional, 1997.

\section{Dae-Kyu Kim}

[Regular member]

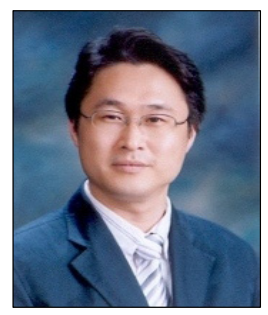

- Dec. 1999 : Louisiana State University, Ph.D.

- Mar. $2002 \sim$ current : Sangmyung University, Dept. of Civil Engineering, Associate Professor

$<$ Research Interests $>$

Geotechnical Engineering, Soils and Foundations, Ground Exploration and Testing, Constitutive Relations, Numerical Analysis, Underground 